\title{
TITLE:
}

\section{Comparative study of phenol and thiophenol adsorption on $\mathrm{Cu}(110)$.}

\section{$\operatorname{AUTHOR}(S)$ :}

Kitaguchi, Y; Habuka, S; Mitsui, T; Okuyama, H; Hatta, S; Aruga, T

\section{CITATION:}

Kitaguchi, Y ...[et al]. Comparative study of phenol and thiophenol adsorption on $\mathrm{Cu}(110)$.. The Journal of chemical physics 2013, 139(4): 044708.

\section{ISSUE DATE:}

2013-07-26

URL:

http://hdl.handle.net/2433/178663

\section{RIGHT:}

(C) 2013 AIP Publishing LLC 


\section{AIP $\substack{\text { meloumalof } \\ \text { Chemical Physics }}^{2}$}

\section{Comparative study of phenol and thiophenol adsorption on $\mathrm{Cu}(110)$}

Y. Kitaguchi, S. Habuka, T. Mitsui, H. Okuyama, S. Hatta et al.

Citation: J. Chem. Phys. 139, 044708 (2013); doi: 10.1063/1.4815968

View online: http://dx.doi.org/10.1063/1.4815968

View Table of Contents: http://jcp.aip.org/resource/1/JCPSA6/v139/i4

Published by the AIP Publishing LLC.

\section{Additional information on J. Chem. Phys.}

Journal Homepage: http://jcp.aip.org/

Journal Information: http://jcp.aip.org/about/about_the_journal

Top downloads: http://jcp.aip.org/features/most_downloaded

Information for Authors: http://jcp.aip.org/authors

\section{ADVERTISEMENT}

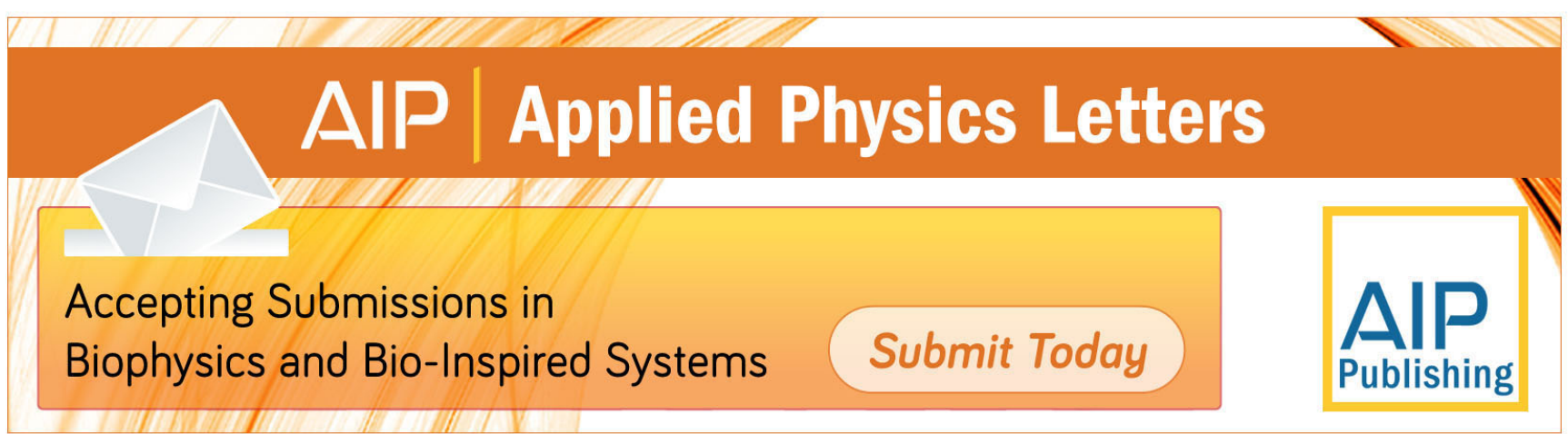




\title{
Comparative study of phenol and thiophenol adsorption on $\mathrm{Cu}(110)$
}

\author{
Y. Kitaguchi, S. Habuka, T. Mitsui, H. Okuyama, ${ }^{\text {a) }}$ S. Hatta, and T. Aruga \\ Department of Chemistry, Graduate School of Science, Kyoto University, Kyoto 606-8502, Japan
}

(Received 22 April 2013; accepted 26 June 2013; published online 26 July 2013)

\begin{abstract}
Adsorption of phenol and thiophenol (benzenethiol) on $\mathrm{Cu}(110)$ is investigated by a scanning tunneling microscope and electron energy loss spectroscopy. Phenol adsorbs intact and forms a cyclic trimer at $78 \mathrm{~K}$. It is dehydrogenated to yield a phenoxy $\left(\mathrm{C}_{6} \mathrm{H}_{5} \mathrm{O}\right)$ group at $300 \mathrm{~K}$. On the other hand, thiophenol is dehydrogenated to a thiophenoxy $\left(\mathrm{C}_{6} \mathrm{H}_{5} \mathrm{~S}\right)$ group even at $78 \mathrm{~K}$. Both products are bonded via chalcogen atom to the short-bridge site with the phenyl ring oriented nearly parallel to the surface. The $\mathrm{C}_{6} \mathrm{H}_{5} \mathrm{O}$ and $\mathrm{C}_{6} \mathrm{H}_{5} \mathrm{~S}$ groups are preferentially assembled into the chains along the [001] and [11̄2] directions, respectively. Dipole-dipole interaction is responsible for the chain growth, while the chain direction is ruled by the steric repulsion between chalcogen atoms and adjacent phenyl ring. This work demonstrates a crucial role of chalcogen atom of phenol species in their overlayer growth on the surface. (C) 2013 AIP Publishing LLC. [http://dx.doi.org/10.1063/1.4815968]
\end{abstract}

\section{INTRODUCTION}

Adsorption of aromatic molecules on solid surfaces has drawn much attention because the organic thin film has potential application in the field of surface engineering. It is essential to understand in detail the microscopic chemical bond and geometry at the interface of organic films and the substrates, which influence the macroscopic properties such as adhesiveness and mechanical resistance. ${ }^{1}$ Phenol has two functional groups, i.e., hydroxyl group and phenyl ring, which can be involved in the interaction with the surface as well as with the neighboring molecules. Therefore, it is important to understand their interplay for the rational functionalization of the interface. It is well established that phenol undergoes partial dehydrogenation to yield a phenoxy $\left(\mathrm{C}_{6} \mathrm{H}_{5} \mathrm{O}\right)$ group on various metal surfaces. ${ }^{2-11}$ By mainly using electron energy loss spectroscopy (EELS), Richardson and Hofmann showed that $\mathrm{C}_{6} \mathrm{H}_{5} \mathrm{O}$ is adsorbed on $\mathrm{Cu}(110)$ with its molecular plane nearly parallel to the surface, based on which the molecule was suggested to interact with the surface via both its aromatic ring and oxygen atom. ${ }^{2}$ However, the details of the binding structure, its temperature dependence, and the effect of intermolecular interaction remain yet to be clarified.

The adsorption of related sulfur-containing species on metal surfaces has also been studied from the viewpoint of surface functionalization with self-assembled monolayers (SAMs) anchored by stable metal-sulfur bonds. ${ }^{12}$ So far the study of thiol-based SAMs has been of considerable interest due to their technological applications in molecular electronic devices, chemical and biochemical sensors, and corrosion inhibitors. ${ }^{13}$ The benzenethiol (thiophenol) molecule, the simplest arenethiol, is analogous to phenol in that both the phenyl ring and the active anchor group (SH) can be involved in the interaction and reaction with the surface. Reflecting higher acidity of the $\mathrm{SH}$ group compared to the $\mathrm{OH}$ group for these compounds, thiophenol is dehydrogenated to thiophe-

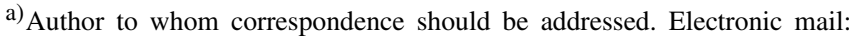
hokuyama@kuchem.kyoto-u.ac.jp
}

noxy $\left(\mathrm{C}_{6} \mathrm{H}_{5} \mathrm{~S}\right)$ species on metal surfaces at lower temperature. The molecular geometry of $\mathrm{C}_{6} \mathrm{H}_{5} \mathrm{~S}$ on $\mathrm{Cu}(110)$ was suggested to be flat-lying in the same way as $\mathrm{C}_{6} \mathrm{H}_{5} \mathrm{O} .{ }^{14,15}$ On other metal surfaces, however, it was suggested that the molecule stands up with the molecular plane tilted out of the surface plane, in contrast to the case of phenoxy group. ${ }^{16-20}$ Thus the functional groups $(\mathrm{O}$ and $\mathrm{S})$ play a key role in optimizing the molecular structure, contributing to both the adsorbateadsorbate and adsorbate-substrate interaction. ${ }^{21,22} \mathrm{~A}$ comparative study of phenoxy and thiophenoxy adsorption would unravel the different roles of $\mathrm{S}$ and $\mathrm{O}$ atoms in the interaction of these bi-functional molecules with the surface.

In this study we comparatively investigate phenol and thiophenol adsorption on $\mathrm{Cu}(110)$ by using a scanning tunneling microscope (STM) and EELS. Phenol adsorbs intact at $78 \mathrm{~K}$ and forms a cyclic trimer via $\mathrm{H}$-bond interaction. It is partially dehydrogenated to yield $\mathrm{C}_{6} \mathrm{H}_{5} \mathrm{O}$ at $300 \mathrm{~K}$, as reported in the literature. The local structure of $\mathrm{C}_{6} \mathrm{H}_{5} \mathrm{O}$ and $\mathrm{C}_{6} \mathrm{H}_{5} \mathrm{~S}$ is qualitatively similar: they are bonded via chalcogen atom to the short-bridge site with the phenyl ring oriented nearly parallel to the surface. The dipole interaction between the molecules causes them to form one-dimensional chains along the [001] and [11 2 ] directions for $\mathrm{C}_{6} \mathrm{H}_{5} \mathrm{O}$ and $\mathrm{C}_{6} \mathrm{H}_{5} \mathrm{~S}$, respectively. It is proposed that the chain direction is ruled by the steric hindrance between chalcogen atom and phenyl ring of adjacent molecule.

\section{EXPERIMENTAL}

The experiments were carried out in an ultrahigh-vacuum chamber equipped with an STM operating at $4.5 \mathrm{~K}$. Phenol, phenol-2,3,4,5,6- $\mathrm{d}_{5}\left(\mathrm{C}_{6} \mathrm{D}_{5} \mathrm{OH}\right)$, and thiophenol were obtained from Aldrich. The single crystalline $\mathrm{Cu}(110)$ surface was cleaned by repeated cycles of argon-ion sputtering and annealing. An electrochemically etched tungsten tip was used as an STM probe. The surface was exposed to the vapors at 78 or $300 \mathrm{~K}$ and subsequently cooled to $4.5 \mathrm{~K}$ for the STM measurement. The registry of the molecules to the surface 

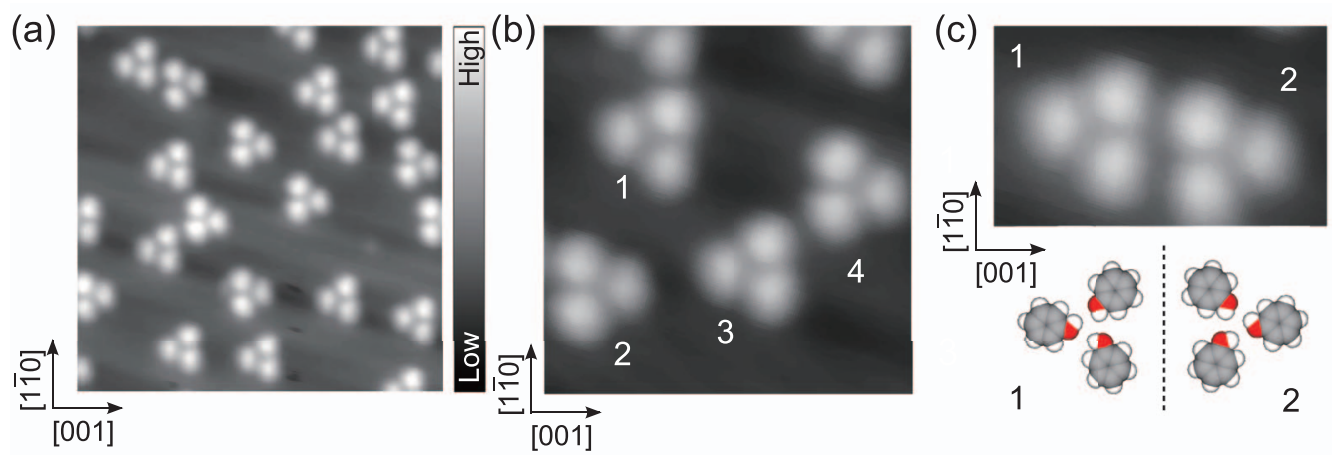

FIG. 1. (a) A typical STM image of $\mathrm{Cu}(110)$ exposed to phenol at $78 \mathrm{~K}$. Three protrusions are observed as a unit, suggesting that phenol forms a cyclic trimer. (b) Reflecting the twofold symmetry of $\mathrm{Cu}(110)$, the trimer shows four equivalent orientations as labeled by "1" - "4". (c) Trimers of two different configurations corresponding to " 1 " and " 2 " in (b), and their model structure. They are optically isomeric with each other with a mirror plane (dashed lines), and are ascribed to clockwise or counterclockwise orientation of H-bonds. The image size is $120 \times 120 \AA^{2}, 54 \times 54 \AA^{2}$, and $22 \times 36 \AA^{2}$ for (a), (b), and (c), respectively. The images were obtained with sample bias voltage $V=86 \mathrm{mV}$ and tunneling current $I=0.2 \mathrm{nA}$.

lattice was determined by their relative location with coadsorbed oxygen atom on the hollow site (Fig. S1 in the supplementary material ${ }^{23}$ ).

The adsorption states were characterized by electron energy loss spectroscopy (EELS, LK-5000, LK Technologies, Inc.). The primary electron energy $7 \mathrm{eV}$, incidence angle $60^{\circ}$, reflection angle $60^{\circ}$ with respect to the surface normal, and typical energy resolution of $3 \mathrm{meV}$ (the full width at half maximum of the elastic peak) were used. The surface was exposed to the vapors through a tube doser and subsequently probed by EELS at 110 or $300 \mathrm{~K}$.

\section{RESULTS AND DISCUSSION}

\section{A. Phenol adsorption}

A typical STM image of $\mathrm{Cu}(110)$ exposed to phenol at $78 \mathrm{~K}$ is shown in Fig. 1(a). The image shows predominantly three protrusions in triangular shape, suggesting that the molecules form a cyclic trimer. As shown later, the EELS confirms that phenol adsorbs intact in a cyclic (closed) $\mathrm{H}$ bond configuration. Cyclic phenol trimer also exists in free jets ${ }^{24,25}$ and solid phase. ${ }^{26}$ Due to the two-fold symmetry of the substrate, four equivalent configurations of trimer are observed (Fig. 1(b)). Two selected configurations are shown in Fig. 1(c), which are mirror images of each other against the reflection plane along [110] (dashed line). The chirality is created from the adsorption and clustering of achiral phenol molecules, as schematically shown in the bottom of Fig. 1(c). The orientation of H-bonds is clockwise or counterclockwise, although we cannot determine which image is ascribed to either configuration. As the exposure increases, the amount of trimer increases but larger clusters are hardly observed, indicating that phenol prefers cyclic (or closed) structure rather than extended chain.

When exposed at $300 \mathrm{~K}$, the surface shows predominantly linear chains of protrusions along the [001] direction (Fig. 2(a)). Phenol is dehydrogenated to yield a phenoxy group $\left(\mathrm{C}_{6} \mathrm{H}_{5} \mathrm{O}\right)$ on $\mathrm{Cu}(110)$ at $300 \mathrm{~K}$, as confirmed by the EELS (described later). Thus individual protrusions in
Fig. 2(a) are ascribed to phenoxy groups. An isolated phenoxy group is imaged as a pair of protrusion and depression (Fig. 2(b)) which reflect the density of states at the phenyl ring and oxygen atom, respectively, in analogy with the hydroxyl group ${ }^{27}$ and methoxy group ${ }^{28}$ on $\mathrm{Cu}(110)$. The images in Fig. 2(b) were obtained at the same area before and after the molecule was manipulated by STM. The lattice of surface $\mathrm{Cu}$ atom superimposed on the images suggests that oxygen atom is bonded to the short-bridge site (shown by a dot), around which the phenyl ring was rotated, as schematically shown in the bottom of Fig. 2(b).

The EEL spectra for phenol adsorption on $\mathrm{Cu}(110)$ are shown in Fig. 3. The upper and lower spectra were recorded at 300 and $110 \mathrm{~K}$, respectively. The $380 \mathrm{meV}$ peaks are characteristic of $\mathrm{sp}^{2} \mathrm{C}-\mathrm{H}$ stretch vibration mode, indicating that the phenyl ring remains intact upon adsorption on the surface at both temperatures. The lower-frequency peaks are assigned with the reference to the gas-phase counterpart, ${ }^{29,30}$ as summarized in Table I. The isotope substitution $\left(\mathrm{C}_{6} \mathrm{D}_{5} \mathrm{OH}\right)$ was employed to reinforce the assignment (Fig. S2 in the supplementary material ${ }^{23}$ ). The $\mathrm{O}-\mathrm{H}$ stretch mode is observed in the lower spectrum of Fig. 3 as a broad structure at

TABLE I. A summary of vibration energies (meV) shown in Fig. 3 and their assignment for phenol/Cu(110).

\begin{tabular}{lccc}
\hline \hline & \multicolumn{2}{c}{ Vibration energy $(\mathrm{meV})$} & \\
\cline { 2 - 3 } Label & $110 \mathrm{~K}$ & $300 \mathrm{~K}$ & Approximate description \\
\hline A & 23,38 & 38 & Cu-ring stretch \\
& & 29 & Cu-O stretch \\
B & 63,85 & 65,85 & C-C out-of-plane bend \\
C & 93,101 & 93 & C-H out-of-plane bend \\
D & 110,144 & 118 & C-H in-plane bend \\
& 154 & 157 & C-O stretch \\
& 173 & & O-H in-plane bend \\
E & 185,198 & 180,190 & C-C stretch \\
F & 378 & 379 & C-H stretch \\
& $\sim 400$ & & O-H stretch \\
\hline
\end{tabular}




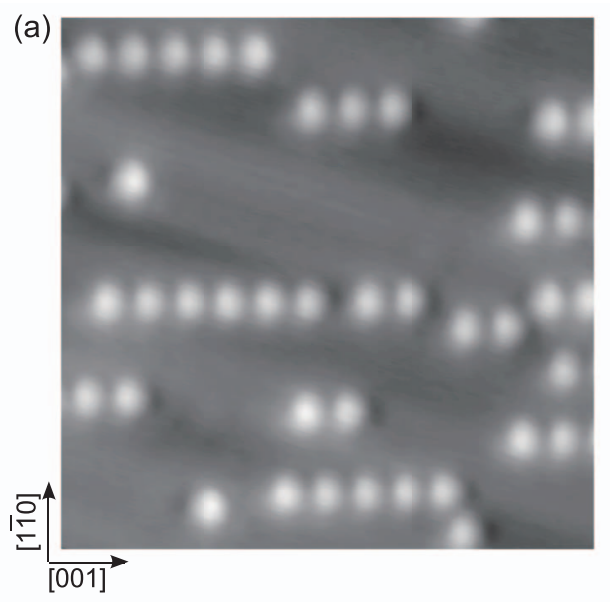

(b)
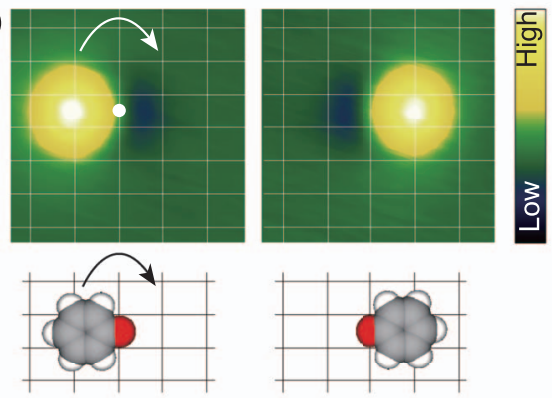

(c)
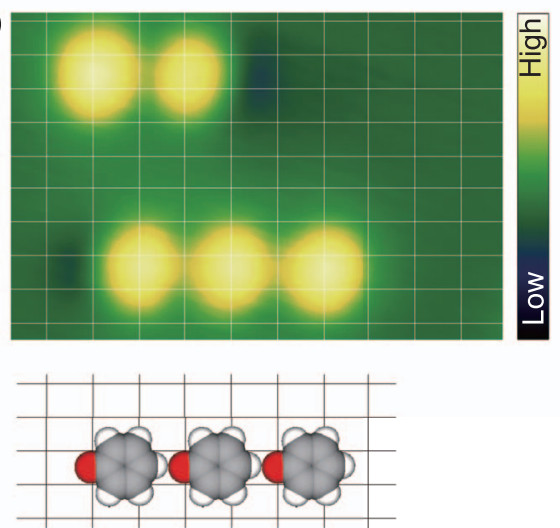

FIG. 2. (a) A typical STM image of $\mathrm{Cu}(110)$ exposed to phenol at $300 \mathrm{~K}$. The phenoxy groups form one-dimensional chains along the [001] direction. (b) STM images of an isolated phenoxy group taken at the same area. The molecule was manipulated by STM to change the orientation. The molecule appears to rotate around the short-bridge site (depicted by a dot) to which oxygen atom is bonded, as schematically shown in the bottom. (c) STM images of phenoxy chains. The molecules are arranged with a period of twoatomic distance (7.2 $\AA$ ). They are oriented in either [001] or [001] direction and in the same direction in each chain. The structures are depicted with van der Waals radii taken into account for each atom. The image size is 97 $\times 97 \AA^{2}, 19 \times 19 \AA^{2}$, and $24 \times 36 \AA^{2}$ for (a), (b), and (c), respectively. The images were obtained at $V=36 \mathrm{mV}$ and $I=5 \mathrm{nA}$.

$\sim 400 \mathrm{meV}$, indicating that the $\mathrm{O}-\mathrm{H}$ bond remains intact at $110 \mathrm{~K}$. We note that while the peak is not clear, it is intrinsic because the same feature is observed for the isotope spectrum in Fig. S2 in the supplementary material. ${ }^{23}$ The signature of the $\mathrm{O}-\mathrm{H}$ bond is also observed at $173 \mathrm{meV}$, which is assigned as the $\mathrm{O}-\mathrm{H}$ bending mode. The $\mathrm{O}-\mathrm{H}$ stretch mode was observed at 450 and $400 \mathrm{meV}$ for vapor (free) and solidphase (cyclic) phenol, respectively. The H-bond interaction

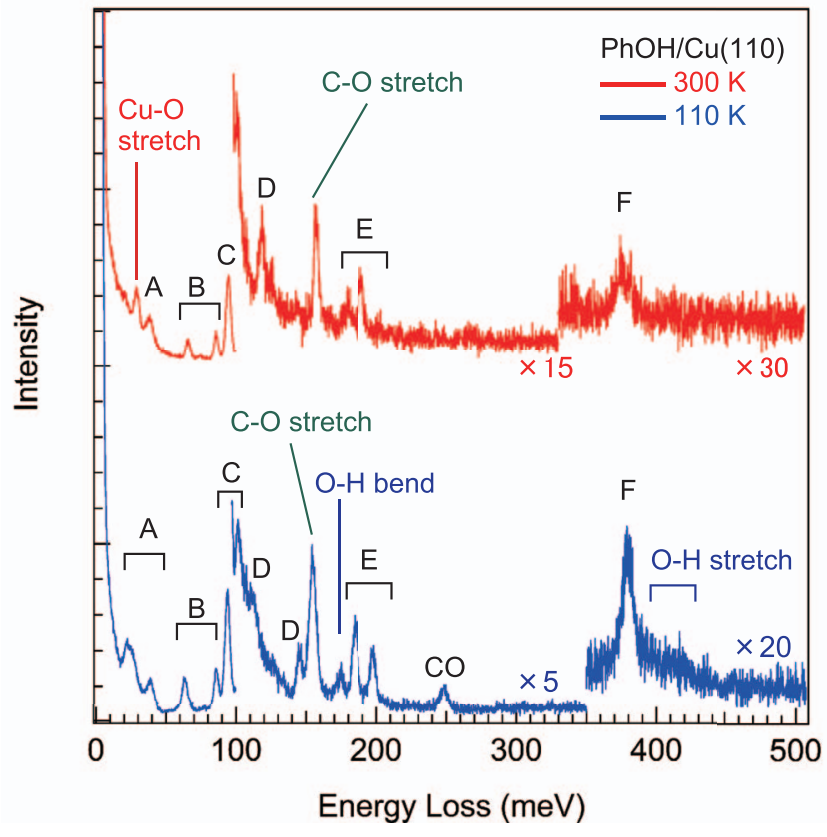

FIG. 3. EEL spectra recorded for $\mathrm{C}_{6} \mathrm{H}_{5} \mathrm{OH} / \mathrm{Cu}(110)$ at $300 \mathrm{~K}$ (top) and 110 $\mathrm{K}$ (bottom). The $\mathrm{O}-\mathrm{H}$ derived peaks at $173 \mathrm{meV}(\mathrm{O}-\mathrm{H}$ in-plane bend) and $\sim 400 \mathrm{meV}$ (O-H stretch) are observed at $110 \mathrm{~K}$, while they are absent at $300 \mathrm{~K}$. The $\mathrm{Cu}-\mathrm{O}$ stretch peak $(29 \mathrm{meV})$ is observed at $300 \mathrm{~K}$, indicating that phenol is dehydrogenated to phenoxy species. The peak assignment is summarized in Table I.

causes the elongation of the $\mathrm{O}-\mathrm{H}$ bonds, giving rise to the decrease of the stretch mode frequency. The absence of the free mode $(450 \mathrm{meV})$ indicates that phenol exists as a cyclic trimer on $\mathrm{Cu}(110)$. On the other hand, the $\mathrm{O}-\mathrm{H}$ related modes are absent in the upper spectrum, indicating that phenol dissociates to a phenoxy group at $300 \mathrm{~K} .^{2}$ The appearance of the $29 \mathrm{meV}$ peak assigned to $\mathrm{O}-\mathrm{Cu}$ stretch is also consistent with the $\mathrm{O}-\mathrm{H}$ cleavage and phenoxy formation. In both spectra, the peaks related to the phenyl ring are almost similar to those for gas-phase phenol, suggesting that the interaction of the phenyl ring with the surface is weak chemisorption, as in the case of benzene on the same surface. ${ }^{31}$ The dominant $93 \mathrm{meV}$ peaks assigned to the $\mathrm{C}-\mathrm{H}$ out-of-plane bend (wag) mode decrease in intensity in the off-specular direction (Fig. S3 in the supplementary material ${ }^{23}$ ). The intense wag mode in the dipole-scattering regime is diagnostic for a phenyl ring parallel to the substrate; both phenol and phenoxy group are adsorbed in flat configuration, as depicted in Figs. 1(c) and 2(b), respectively.

\section{B. Thiophenol adsorption}

A typical STM image of $\mathrm{Cu}(110)$ exposed to thiophenol at $78 \mathrm{~K}$ is shown in Fig. 4(a). In contrast to the case of phenol, individual molecules are isolated and imaged as a protrusion accompanied with a tail. Similar images were observed for thiophenoxy groups $\left(\mathrm{C}_{6} \mathrm{H}_{5} \mathrm{~S}\right)$ on $\mathrm{Cu}(111)^{32,33}$ and $\mathrm{Au}(111) .^{34}$ The EELS shows no peak derived from $\mathrm{S}-\mathrm{H}$ bond $(\sim 300 \mathrm{meV})$ at $110 \mathrm{~K}$ (lower in Fig. 5) as well as at 300 $\mathrm{K}$ (upper). Therefore we assign individual STM images in Fig. 4(a) as thiophenoxy species and attribute the protrusion 
(a)

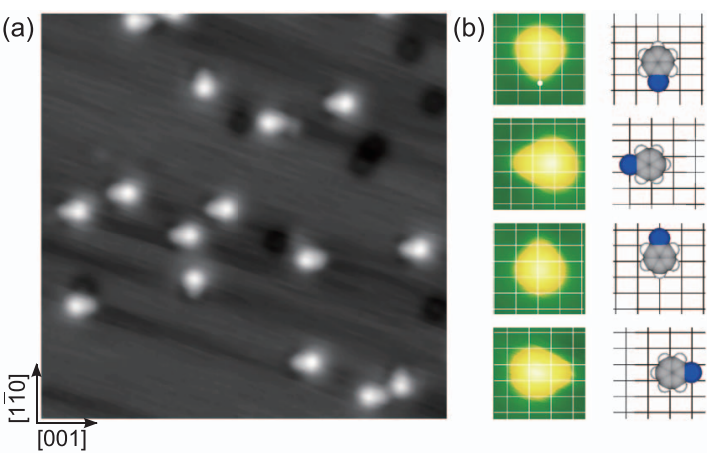

TABLE II. A summary of vibration energies (meV) shown in Fig. 5 and their assignment for thiophenol/ $\mathrm{Cu}(110)$.

\begin{tabular}{lccc}
\hline \hline & \multicolumn{2}{c}{ Vibration energy $(\mathrm{meV})$} & \\
\cline { 2 - 3 } Label & $110 \mathrm{~K}$ & $300 \mathrm{~K}$ & \\
\hline A & 26,35 & 23,36 & Approximate description \\
B & 58,84 & 58,83 & C-C out-of-plane bend \\
C & 91 & 92 & C-H out-of-plane bend \\
D & $125,132,143$ & $121,132,144$ & C-H in-plane bend \\
E & 180,196 & 180,190 & C-C stretch \\
F & 378 & 375 & C-H stretch \\
\hline \hline
\end{tabular}

the four configurations around the short-bridge site (shown by a dot in the top image of Fig. 4(b)), suggesting that it is bonded via sulfur atom to the short-bridge site. We note that the local adsorption structure is similar between $\mathrm{C}_{6} \mathrm{H}_{5} \mathrm{O}$ and $\mathrm{C}_{6} \mathrm{H}_{5} \mathrm{~S}$ groups, except that the [110] orientation is additionally observed for the latter. At $300 \mathrm{~K}$ (Fig. 6), the thiophenoxy groups are predominantly oriented along [001]; the [1110] species turns into the [001] orientation by thermal activation, indicating that the [001] species is thermodynamically stable. It is notable that the $\mathrm{C}_{6} \mathrm{H}_{5} \mathrm{~S}$ groups are preferentially arranged along the [1 $1 \overline{1} 2]$ or [ $[112]$ direction, while the $\mathrm{C}_{6} \mathrm{H}_{5} \mathrm{O}$ groups are predominantly arranged along the [001] direction (Fig. 2(a)). The difference in the chain direction implies the different role of chalcogen atoms in the chain assembly of the molecules.

\section{Mechanism of chain formation}

The phenoxy $\left(\mathrm{C}_{6} \mathrm{H}_{5} \mathrm{O}\right)$ groups are assembled into the chain along the [001] direction with the interval of two-atomic distance of $\mathrm{Cu}$ lattice (7.2 $\AA$ ), as shown in Fig. 2(c). On the other hand, the thiophenoxy $\left(\mathrm{C}_{6} \mathrm{H}_{5} \mathrm{~S}\right)$ groups favor the chain assembly along the [11 2 ] or [112] direction (two-atomic distance along [001] and one-atomic distance along [110], as shown in Fig. 6(b)). The schematic structures are depicted with the molecular dimensions assumed to be same as free $\mathrm{C}_{6} \mathrm{H}_{5} \mathrm{O}(\mathrm{S})$ radicals $^{35,36}$ and van der Waals radii for each atom. The molecules are oriented in the same direction in each chain, and thus, the electrostatic dipole-dipole interaction is most likely responsible for the preferential chain growth for both molecules. The inter-row coupling observed for thiophenoxy species in Fig. 6 also supports the dipole mechanism; the molecules in adjacent rows are always pointing in opposite directions, as shown in the inset. Electrostatic interaction between organic molecules plays a key role in onedimensional ${ }^{21,37,38}$ and two-dimensional ${ }^{39-43}$ molecular assemblies on metal surfaces. Bartels and co-workers reported that thiophenoxy groups are assembled on $\mathrm{Cu}(111)$, in such a way that sulfur atom interacts preferentially with $\mathrm{H}$ atom in the ortho position of adjacent molecule. ${ }^{32}$ This selective $\mathrm{C}-\mathrm{H} \cdots \mathrm{S}$ interaction (a kind of hydrogen bond) was argued in term of charge density difference between the positions of $\mathrm{H}$ atom. For the assembly on $\mathrm{Cu}(110)$, no preference of ortho position is observed as shown in Fig. 6(b), indicating that the mechanism of interaction and assembly pattern critically
FIG. 5. EEL spectra recorded for $\mathrm{C}_{6} \mathrm{H}_{5} \mathrm{SH} / \mathrm{Cu}(110)$ at $300 \mathrm{~K}$ (top) and $110 \mathrm{~K}$ (bottom). Either spectrum shows no S-H stretch peak at $\sim 300 \mathrm{meV}$, indicating that thiophenol is dehydrogenated to thiophenoxy species even at $110 \mathrm{~K}$. The peak assignment is summarized in Table II. 


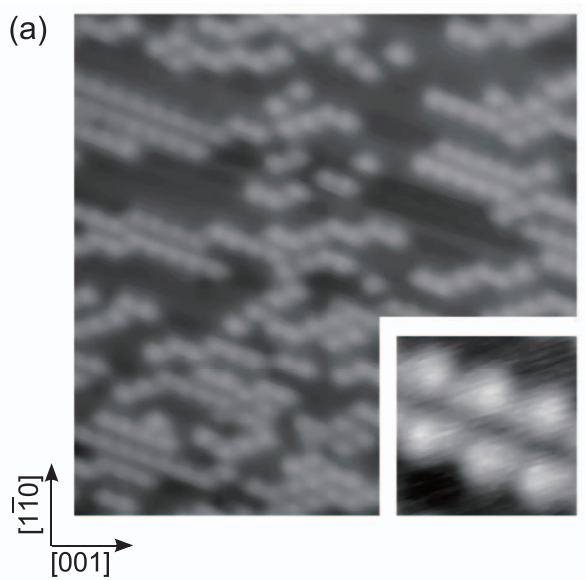

(b)

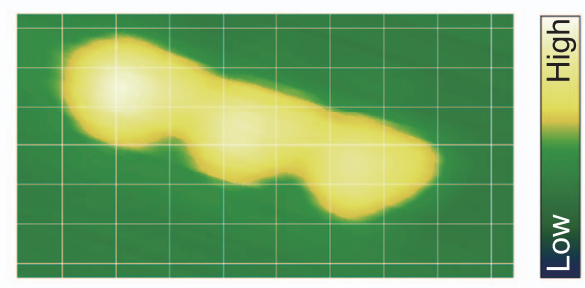

(c)

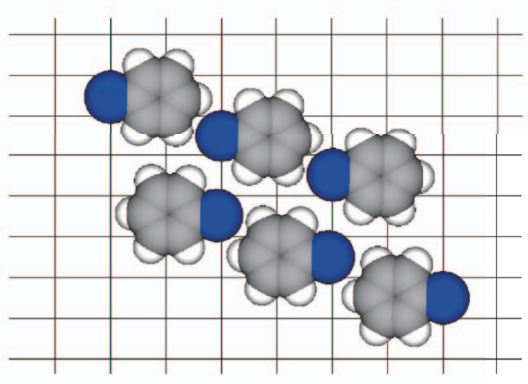

FIG. 6. (a) A typical STM image of $\mathrm{Cu}(110)$ exposed to thiophenol at $300 \mathrm{~K}$ $(V=86 \mathrm{mV}$ and $I=2 \mathrm{nA})$. Thiophenoxy groups are preferentially arranged along the [11 2 ] or [112] directions. The inset shows a magnified image of two adjacent chains, showing inter-chain coupling $(V=50 \mathrm{mV}$ and $I=1$ $n A)$. (b) Enlarged image of a thiophenoxy chain with the surface lattice superimposed $(V=50 \mathrm{mV}$ and $I=5 \mathrm{nA})$. The corresponding model structure is shown, where the molecules are depicted with van der Waals radii taken into account for each atom. The "large" sulfur atom prevents the molecules from being arranged along the [001] direction as phenoxy groups. The illustration shows two rows of thiophenoxy in the inset in (a), which represents the positional relationship across the rows as well as along the row. The image size is $190 \times 190 \AA^{2}, 22 \times 22 \AA^{2}$, and $17 \times 31 \AA^{2}$ for (a), inset in (a) and (b), respectively.

depend on the substrate structure. In general, molecular assembly is ruled by the interplay between moleculemolecule interaction and molecule-substrate interaction. We propose that the latter contributes more dominantly on $\mathrm{Cu}(110)$ than on $\mathrm{Cu}(111)$. When the STM image was obtained at $78 \mathrm{~K}$, we observed the thiophenoxy group is immobile on $\mathrm{Cu}(110)$. This is in contrast to the case of $\mathrm{Cu}(111)$, where it is dynamically rotating and migrating even at $60 \mathrm{~K}{ }^{44}$ This suggests that the molecule binds more strongly on $\mathrm{Cu}(110)$, where the orientation of individual molecules is fixed along the [001] direction so that they cannot be interacted with each other via $\mathrm{H}$ atom of particular site. The molecules are propelled into the chain by complementary dipole-dipole interaction.

Then what causes the difference in the chain direction between $\mathrm{C}_{6} \mathrm{H}_{5} \mathrm{O}$ and $\mathrm{C}_{6} \mathrm{H}_{5} \mathrm{~S}$ groups? The chain structures depicted in the bottom of Figs. 2 and 6 for $\mathrm{C}_{6} \mathrm{H}_{5} \mathrm{O}$ and $\mathrm{C}_{6} \mathrm{H}_{5} \mathrm{~S}$ groups, respectively, with their van der Waals radii taken into account, illustrate how the chain direction is ruled by chalcogen atoms: $\mathrm{C}_{6} \mathrm{H}_{5} \mathrm{~S}$ groups are arranged along the [112] or [112] direction so that they maximize the benefit from the dipole interaction while avoiding the steric hindrance between sulfur atom and the adjacent phenyl ring. Thus the chain direction is qualitatively explained in terms of the difference of the van der Waals radii between oxygen and sulfur atoms.

\section{SUMMARY}

The adsorption and molecular interaction of phenol and thiophenol molecules on $\mathrm{Cu}(110)$ are studied by STM and EELS. Phenol adsorbs intact while thiophenol leaves S-H hydrogen to yield a thiophenoxy $\left(\mathrm{C}_{6} \mathrm{H}_{5} \mathrm{~S}\right)$ group at $78 \mathrm{~K}$. The former is dehydrogenated to yield a phenoxy $\left(\mathrm{C}_{6} \mathrm{H}_{5} \mathrm{O}\right)$ group at $300 \mathrm{~K}$. Both phenoxy and thiophenoxy species show similar local structures; they are bonded via chalcogen atoms to the short-bridge site with the phenyl ring oriented nearly parallel to the surface. On the other hand, they prefer chain growth along different directions, which is ruled by the interplay between attractive dipole-dipole interaction and the steric repulsion between chalcogen atoms and phenyl ring.

${ }^{1}$ J. Robins, Structural Adhesives: Chemistry and Techniology (Plenum Press, New York, 1986).

${ }^{2}$ N. V. Richardson and P. Hofmann, Vacuum 33, 793 (1983).

${ }^{3}$ F. Lu, G. N. Salaita, L. Laguren-Davidson, D. A. Stern, E. Wellner, D. G. Frank, N. Batina, D. C. Zapien, N. Walton, and A. T. Hubbard, Langmuir 4, 637 (1988).

${ }^{4}$ A. K. Myers and J. B. Benzigner, Langmuir 5, 1270 (1989).

${ }^{5}$ X. Xu and C. M. Friend, J. Phys. Chem. 93, 8072 (1989).

${ }^{6}$ J. G. Serafin and C. M. Friend, Surf. Sci. 209, L163 (1989).

${ }^{7}$ M. G. Ramsey, G. Rosina, D. Steinmüller, H. H. Graen, and F. P. Netzer, Surf. Sci. 232, 266 (1990).

${ }^{8}$ H. Bu, P. Bertrand, and J. W. Rabalais, J. Chem. Phys. 98, 5855 (1993).

${ }^{9}$ X.-C. Guo and R. J. Madix, Surf. Sci. 341, L1065 (1995).

${ }^{10}$ B. Bartlett, J. M. Valdisera, and J. N. Russell, Jr., Surf. Sci. 442, 265 (1999).

${ }^{11}$ J. Lee, S. Ryu, and S. K. Kim, Surf. Sci. 481, 163 (2001).

${ }^{12}$ D. Chen and J. Li, Surf. Sci. Rep. 61, 445 (2006).

${ }^{13}$ J. C. Love, L. A. Estroff, J. K. Kriebel, R. G. Nuzzo, and G. M. Whitesides, Chem. Rev. 105, 1103 (2005).

${ }^{14}$ W. Shen, G. L. Nyberg, and J. Liesegang, Surf. Sci. 298, 143 (1993).

${ }^{15}$ P. A. Agron, T. A. Carlson, W. B. Dress, and G. L. Nyberg, J. Electron Spectrosc. Relat. Phenom. 42, 313 (1987).

${ }^{16}$ V. D. Castro, F. Bussolotti, and C. Mariani, Surf. Sci. 598, 218 (2005).

${ }^{17}$ D. R. Huntley, J. Phys. Chem. 96, 4550 (1992).

${ }^{18}$ C. W. J. Bol, C. M. Friend, and X. Xu, Langmuir 12, 6083 (1996).

${ }^{19}$ D. M. Jaffey and R. J. Madix, J. Am. Chem. Soc. 116, 3020 (1994).

${ }^{20}$ J. Y. Gui, D. A. Stern, D. G. Frank, F. Lu, D. C. Zapien, and A. T. Hubbard, Langmuir. 7, 955 (1991).

${ }^{21}$ G. Pawin, U. Solanki, K-.Y. Kwon, K. L. Wong, X. Lin, T. Jiao, and L. Bartels, J. Am. Chem. Soc. 129, 12056 (2007).

${ }^{22}$ N. Jayanthi, J. Cruz, and T. Pandiyan, Chem. Phys. Lett. 455, 64 (2008).

${ }^{23} \mathrm{See}$ supplementary material at http://dx.doi.org/10.1063/1.4815968 for the determination of the adsorption sites, EEL spectrum for $\mathrm{C}_{6} \mathrm{D}_{5} \mathrm{OH} / \mathrm{Cu}(110)$, and the angle dependence of the intensity of the wag (out-of-plane $\mathrm{C}-\mathrm{H}$ bend) mode.

${ }^{24}$ K. Fuke and K. Kaya, Chem. Phys. Lett. 94, 97 (1983).

${ }^{25}$ T. Ebata, T. Watanabe, and N. Mikami, J. Phys. Chem. 99, 5761 (1995). 
${ }^{26}$ V. E. Zavodnik, V. K. Belśkii, and P. M. Zorkii, J. Struct. Chem. 28, 793 (1987).

${ }^{27}$ T. Kumagai, M. Kaizu, H. Okuyama, S. Hatta, T. Aruga, I. Hamada, and Y. Morikawa, Phys. Rev. B. 79, 035423 (2009).

${ }^{28}$ Y. Kitaguchi, A. Shiotari, H. Okuyama, S. Hatta, and T. Aruga, J. Chem. Phys. 134, 174703 (2011).

${ }^{29}$ W. Roth, P. Imhof, M. Gerhards, S. Schmm, and K. Kleinermanns, Chem. Phys. 252, 247 (2000).

${ }^{30}$ J. C. Evans, Spectrochim. Acta 16, 1382 (1960).

${ }^{31}$ N. Atodiresei, V. Caciuc, P. Lazíc, and S. Blugel, Phys. Rev. Lett. 102, 136809 (2009).

${ }^{32}$ K. Wong, K-.Y. Kwon, B. V. Rao, A. Liu, and L. Bartels, J. Am. Chem. Soc. 126, 7762 (2004).

${ }^{33}$ K-.Y. Kwon, G. Pawin, K. L. Wong, E. Peters, D. Kim, S. Hong, T. S. Rahman, M. Marsella, and L. Bartels, J. Am. Chem. Soc. 131, 5540 (2009).

${ }^{34}$ P. Maksymovych and J. T. Yates, Jr., J. Am. Chem. Soc. 130, 7518 (2008).

${ }^{35}$ R. Liu, K. Morokuma, A. M. Mebel, and M. C. Liu, J. Phys. Chem. 100, 9314 (1996).
${ }^{36}$ L. Rottmannová, A. Vagánek, J. Rimarík, V. Lukeś, and E. Klein, Acta Chim. Slov. 5, 37 (2012).

${ }^{37}$ J. V. Barth, J. Weckesser, C. Cai, P. Günter, L. Bürgi, O. Jeandupeux, and K. Kern, Angew. Chem., Int. Ed. 39, 1230 (2000).

${ }^{38}$ D. L. Keeling, N. S. Oxtoby, C. Wilson, M. J. Humphry, N. R. Champness, and P. H. Beton, Nano Lett. 3, 9 (2003).

${ }^{39}$ T. Yokoyama, S. Yokoyama, T. Kamikado, Y. Okuno, and S. Mashiko, Nature (London) 413, 619 (2001).

${ }^{40}$ J. A. Theobald, N. S. Oxtoby, M. A. Phillips, N. R. Champness, and P. H. Beton, Nature (London) 424, 1029 (2003).

${ }^{41}$ G. Pawin, K. L. Wong, K-.Y. Kwon, and L. Bartels, Science 313, 961 (2006).

${ }^{42}$ M. Lackinger, S. Griessl, L. Kampschulte, F. Jamitzky, and W. M. Heckl, Small 1, 532 (2005)

${ }^{43}$ P. Jiang, K. Deng, D. Fichou, S-.S. Xie, A. Nion, and C. Wang, Langmuir 25, 5012 (2009)

${ }^{44}$ K. L. Wong, K-.Y. Kwon, and L. Bartels, Appl. Phys. Lett. 88, 183106 (2006). 